\title{
EVALUASI PENURUNAN PONDASI TANGKI MINYAK SESUAI API 653
}

\author{
oleh : \\ Budi Satiawan \\ Teknik Sipil Universitas Muhammadiyah Jakarta \\ Email : budi.satiawan@umj.ac.id \\ Tanjung Rahayu Raswitaningrum \\ Teknik Sipil Universitas Muhammadiyah Jakarta \\ Email : tanjung.rahayu@umj.ac.id
}

\begin{abstract}
Abstrak : Lapangan pengolahan minyak dan gas menyimpan banyak fasilitas peralatan berupa tangki pelat baja yang melayani penyimpanan fluida diantaranya berupa minyak. Beberapa masalah yang mungkin terjadi pada tangki yang telah beroperasi sekian lama adalah penurunan pada pondasi. Suatu tangki yang telah beroperasi sekitar 20 tahun terindikasi secara visual telah mengalami kemiringan. Indikasi awal terhadap kemiringan tersebut adalah telah terjadinya penurunan tidak seragam (differential settlement) pada pondasi tangki. Penelitian dilakukan untuk mengetahui apakah tangki tersebut masih dapat digunakan dan dalam kondisi aman untuk dioperasikan atau memerlukan perbaikan. Penelitian ini akan mengevaluasi penurunan yang terjadi pada tangki tersebut sesuai metode analisis pada American Petroleum Institute (API) 653. API 653, Tank Inspection, Repair, Alteration, and Reconstruction, fifth edition memberikan rekomendasi metoda untuk melakukan evaluasi terhadap penurunan tanah (settlement). Hasil penelitian menunjukkan bahwa penurunan tangki di beberapa titik telah melebih batas penurunan maksimum sehingga diperlukan adanya perbaikan lebih lanjut.
\end{abstract}

Kata Kunci : tangki minyak, tipe tangki, penurunan, API 653,

Abstract: The field of oil and gas processing have many equipment facilities such as steel plate tanks serving fluid storage, including oil. Some problems that may occur in tanks that have been operating for a long periode are about the problem of settlement on the foundation. A tank that has been operating for about 20 years is visually indicated to have a settlement problem. The initial indication is suspected that there has been a non-uniform settlement (differential settlement) on the tank foundation. The research was conducted to determine whether the tank can still be used and is in a safe condition to be operated or need an improvement. This research will evaluate the settlement that occurs in the tank with the analysis method according to American Petroleum Institute (API) 653. API 653, Tank Inspection, Repair, Alteration, and Reconstruction recommends methods for evaluating settlement. The results of research showed that the settlement at several points has exceeded the maximum settlement so the futher improvements were needed.

Keywords: Oil tank, tank type, settlement, API 653

\section{Pendahuluan}

Di dalam fasilitas infrastruktur pengolahan minyak dan gas banyak ditemui fasilitas penyimpanan fluida yang biasa dikenal dengan tangki. Nurpadmi (2018) menyatakan bahwa fungsi tangki atau sering disebut tangki timbun adalah untuk menyimpan minyak mentah atau minyak hasil dari proses kilang gas, chemical, dan lain-lain.

Perencanaan desain tangki yang tepat dapat mengurangi risiko kegagalan baik dalam proses fabrikasi maupun penggunaannya. 
Dalam tahap perencanaan pondasi, akan dilakukan perhitungan terhadap stabilitas pondasi meliputi stabilitas daya dukung saat kondisi pondasi menerima beban tetap meliputi berat sendiri tangki beserta aksesorisnya, beban fluida yang ditampung di dalam tangki dan beban hidup yang bekerja pada atap tangki maupun pembebanan yang sifatnya sementara (beban gempa, beban angin serta beban isi saat dilakukan hydrostatic test). Faktor yang tidak kalah pentingnya untuk dipertimbangkan saat tahap perencanaan adalah perhitungan terhadap penurunan jangka pendek dan jangka panjang yang dapat terjadi sesuai kondisi tanah setempat yang manakala akibat pertimbangan penurunan tersebut akan dapat mempengaruhi dari jenis tipe pondasi yang akan digunakan.

Beberapa kasus penurunan pondasi yang seringkali ditemukan pada fasilitas penyimpanan fluida (tangki) diantaranya adalah masalah penurunan dari pondasi tangki baik pada saat sebelum dioperasikan (saat hydrostatic test) maupun pada kondisi setelah dioperasikan jangka panjang.

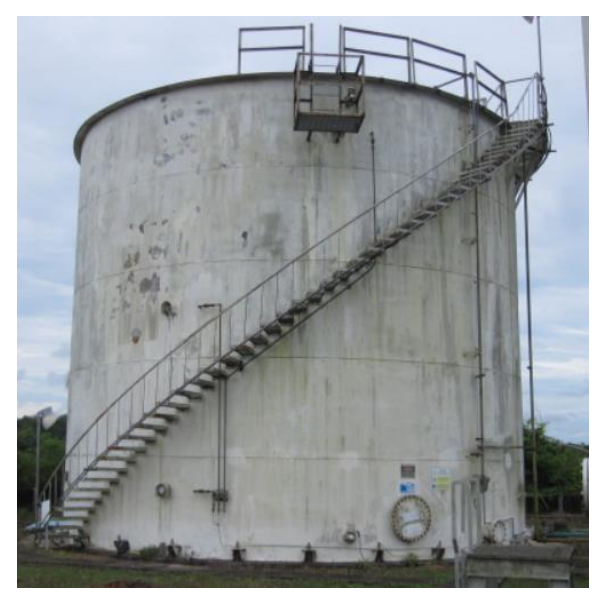

Gambar 1. Tangki

Penelitian ini dilakukan karena ditemukan permasalahan di suatu lapangan infrastruktur migas. Tangki yang merupakan tempat penyimpanan fluida berupa minyak dengan dengan tipe tangki fixed roof terlihat secara visual telah mengalami kemiringan. Indikasi awal terhadap kemiringan tersebut adalah telah terjadi penurunan tidak seragam (differential settlement) pada pondasi tangki.

\section{Tinjauan Pustaka}

Secara umum, tangki terdiri dari:

- roof plate

- shell plate

- annular plate

- bottom plate
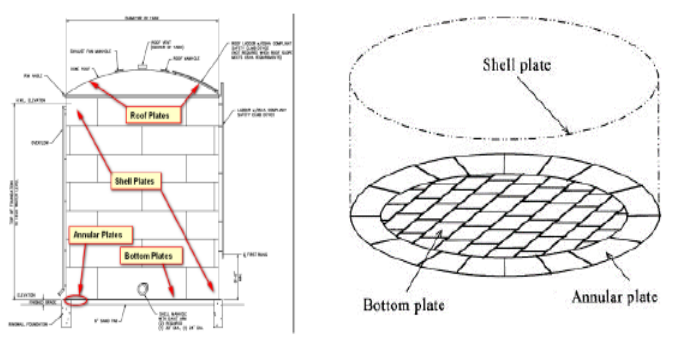

Gambar 2. Komponen tangki

(Widawardhana, 2020)

Pertimbangan desain menurut Widawardhana (2020) adalah:

1. volume tangki maksimum

2. berat komponen utama, pelengkap (apputenance), dan aksesoris

3. tinggi dan diameter tangki

4. ketinggian cairan (liquid level)

5. berat jenis cairan (specific gravity)

6. kecepatan angin

7. beban gempa

8. kombinasi pembebanan

9. penyelidikan tanah

10. daya dukung tanah

11. penurunan tanah

Berdasarkan API 650, fondasi tangki dapat dikategorikan menjadi:

1. pondasi tanah tanpa ringwall (earth foundations without a ringwall) 
2. pondasi tanah dengan ringwall beton (earth foundations with a concrete ringwall)

3. fondasi tanah dengan ringwall batu pecahan kerikil (earth foundations with a crushed stone and gravel ringwall)

4. Fondasi rakit (slab foundation)

Berdasarkan API 653, penurunan yang terjadi pada tangki dapat dikategorikan menjadi:

1. penurunan seragam (uniform settlement) Kondisi penurunan seragam ini tidak mengakibatkan kenaikan tegangan pada struktur tangki, tetapi kemungkinan konsentrasi tegangan dapat terjadi pada koneksi hubungan antara tangki dengan sistem perpipaan yang ada, noozle area atapun attachment yang terpasang pada struktur tangki dan tidak dapat mengikuti penurunan seragam yang terjadi pada dinding tangki.

2. Rigid body tilting of a tank (planar tilt)

Kondisi ini dapat diidealisasikan sebagai kondisi tangki yang miring (tilting) dengan anggapan tangki berotasi dalam suatu bidang rata. Dari terjadinya kemiringan tangki ini dapat mengakibatkan terjadinya peningkatan tegangan pada dinding tangki (hoop stress) yang disebabkan oleh kenaikan elevasi fluida disisi dalam tangki yang berada pada penurunan area di elevasi rendah. Untuk tangki dengan tipe floating roof, kondisi kemiringan yang besar akan dapat mengakibatkan gangguan pengoperasian dari pergerakan naik turunnya atap.

3. Settle in a non-planar configuration

Kondisi ini menunjukkan tangki yang berotasi tetapi tidak pada bidang yang rata akibat dari bentuk tangki sendiri yang sifatnya adalah fleksibel. Efek dari sifat fleksibilitas tangki dapat mengakibatkan perubahan dari bentuk kebulatan tangki (roundess) yang dapat berakibat penambahan tegangan atau integritas dari struktur utama penahan atap seperti rafter, kolom atapun girder. Kondisi penurunan ini dapat mengakibatkan pembentukan suatu bidang bidang datar setempat pada dinding tangki serta mempengaruhi integrity dari pipa yang terkoneksi pada dinding tangki.

Untuk mengetahui efek dari penurunan tanah terhadap kondisi kemiringan tangki dapat digunakan acuan dari rekomendasi API 653 Annex B. Standar Annex B ini membahas mengenai bagaimana melakukan evaluasi terhadap sisi dasar tangki (evaluation of tank bottom settlement). Sub bab Annex B.2 API 653 menjelaskan bagaimana menentukan evaluasi besarnya pengukuran settlement yang terjadi dan jumlah titik pengukuran yang diperlukan, sedangkan sub bab Annex B.3 API 653 menjelaskan bagaimana menghitung besaran penurunan yang diijinkan.

Perhitungan kebutuhan jumlah titik sesuai diameter tangki adalah

$\mathrm{N}=\mathrm{D} / 10$

Dimana:

$\mathrm{N}=$ Jumlah minimum titik pengukuran yang dibutuhkan dengan tidak kurang dari 8 titik. Jarak radius maksimum tiap titik tidak kurang dari $32 \mathrm{ft}(9,75 \mathrm{~m})$

$\mathrm{D}=$ Diameter tangki $(\mathrm{ft})$ 


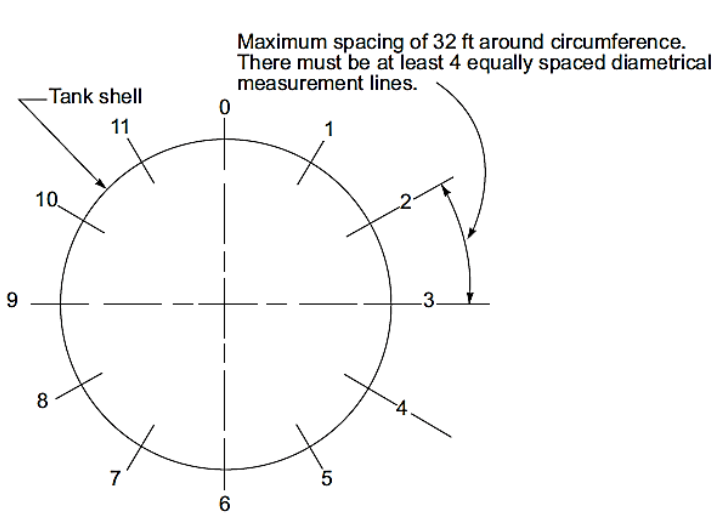

NOTE 1 There must be at least eight settlement points. The maximum spacing of the settlement points is $32 \mathrm{ft}$ around the circumference.

NOTE 2 Points shall be equally spaced around the tank shell. See 12.5.1.2 for method of determining the number of measurement points.

Gambar 3. Potongan pondasi tangki (API Standard 653, 2014)

API 653 memberikan ilustrasi besarnya penurunan tangki tipe rigid tilt plane dalam bentuk kurva cosine dimana nilai elevasi settlement (Elev pred.) dihitung dengan menggunakan persamaan sebagai berikut:

Elev pred $=a+b \times \cos (\theta+c)$

Nilai a, b dan c dapat dihitung dengan cara coba-coba sehingga diperoleh nilai $\mathrm{R}$ yang dianggap valid untuk tipe penurunan rigid tilt plane yaitu lebih besar atau sama dengan 0,9 .

$R^{2}=\frac{\left(s_{y y}-S S E\right)}{S_{y y}}$

Dimana:

Syy = Jumlah kuadrat dari perbedaan antara ketinggian rata-rata yang diukur terhadap ketinggian titik yang ditinjau

SSE = Jumlah kuadrat dari perbedaan antara ketinggian yang diukur dan diperkirakan

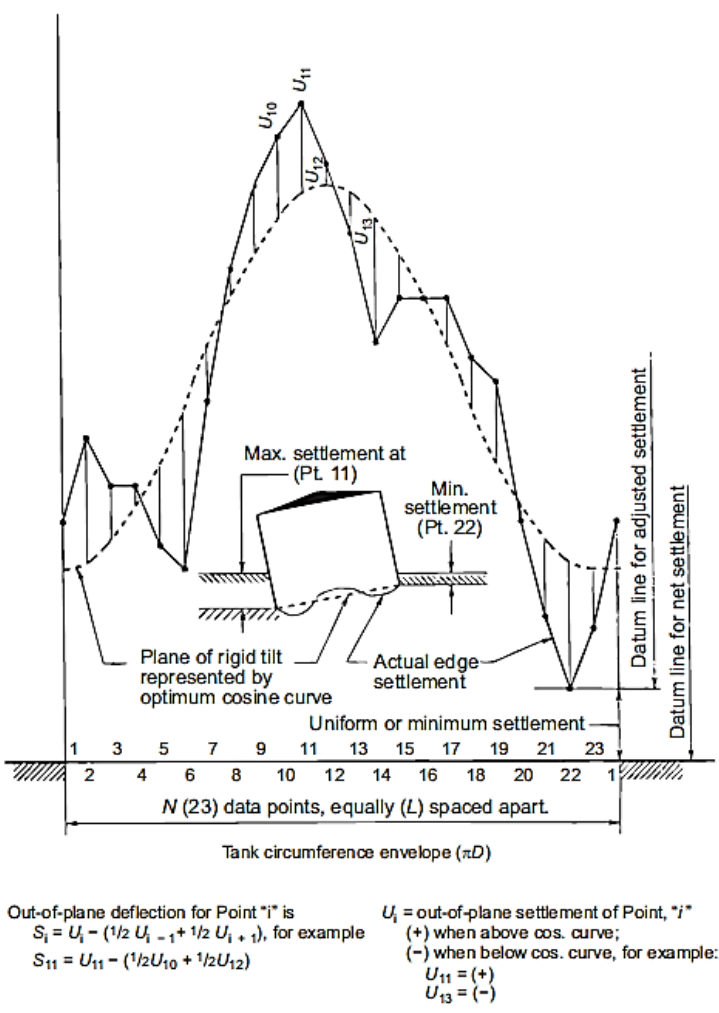

Gambar 4. Gambar grafik kurva cosine (API Standard 653, 2014)

Out-of-plane deflection, Si untuk point i dapat dihitung menggunakan persamaan:

$\mathrm{Si}=\mathrm{Ui}-(1 / 2 \mathrm{Ui}-1+1 / 2 \mathrm{Ui}+1)$

Out-of-plane settlement, Ui untuk point i dapat dihitung berdasarkan selisih antara settlement actual (pengukuran) terhadap elevasi settlement berdasarkan kurva cosine dimana bernilai positif (+) bila elevasi pengukuran di lapangan berada di atas kurva cosine dan sebaliknya (-) bila berada di bawah kurva cosine.

Untuk melakukan evaluasi penurunan yang terjadi pada tangki (shell settlement) akan digunakan evaluasi terhadap batasan settlement yang diijinkan dimana penurunan yang terjadi tidak melebihi penurunan maksimum (permissible out-ofplane settlement, Smax).

$$
S_{\max }=\frac{\left(L^{2} \times Y \times 11\right)}{2[(E \times H)]}
$$


Dimana:

Smax = penurunan maksimum yang diizinkan (ft)

$\mathrm{L} \quad=$ panjang busur antara titik-titik pengukuran $(\mathrm{ft})$

$\mathrm{Y} \quad=$ tegangan leleh material $\left(\mathrm{lb} / \mathrm{ft}^{2}\right)$

$\mathrm{E} \quad=$ modulus Young $\left(\mathrm{lb} / \mathrm{ft}^{2}\right)$

$\mathrm{H} \quad=$ tinggi tangki $(\mathrm{ft})$

\section{Metodologi Penelitian}

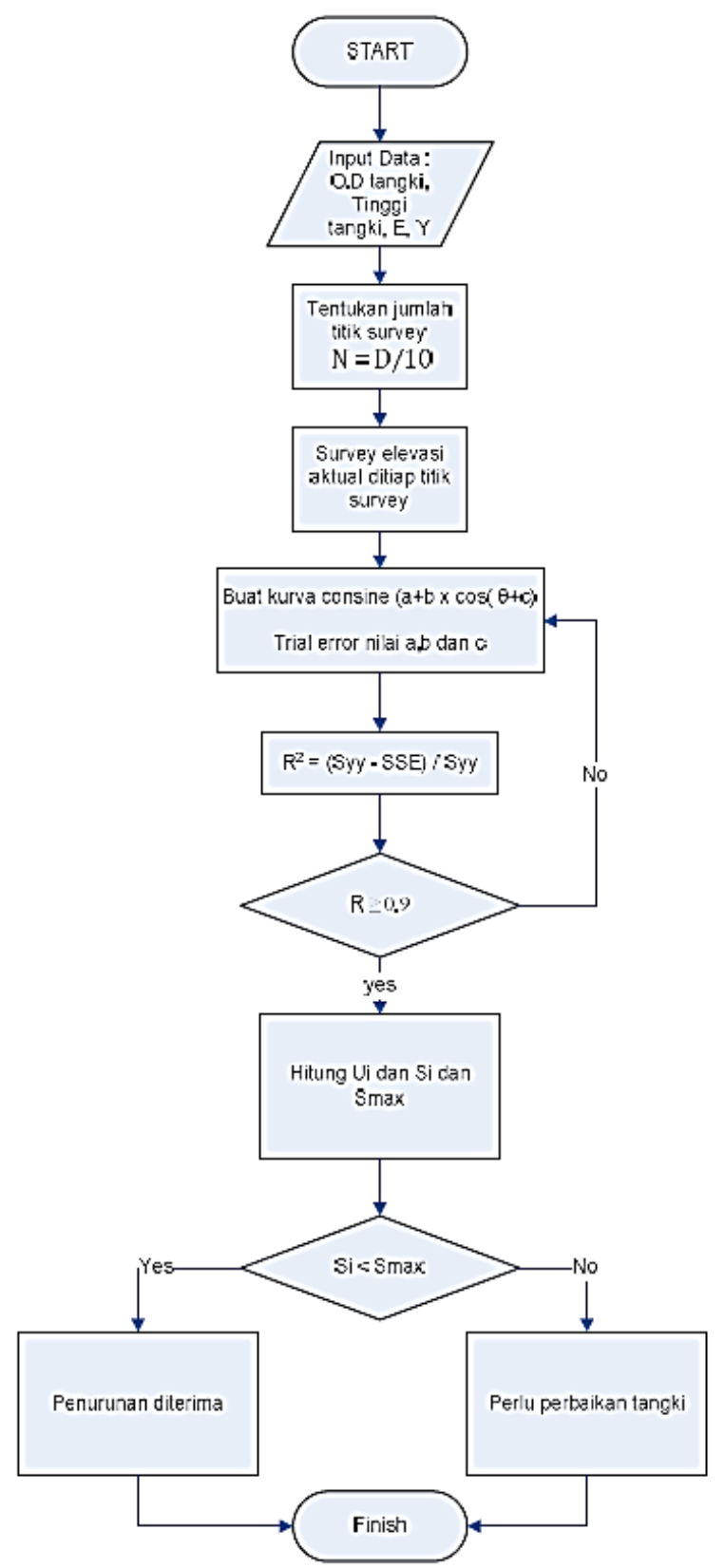

Gambar 5. Flowchart simulasi
Proses pengambilan data hingga hasil penelitian dapat dilihat pada flowchart di atas.

Dalam melakukan evaluasi penurunan tangki, akan dilakukan pengambilan data pengukuran elevasi pada permukaan dasar tangki (eksternal tangki) dan analisis berdasarkan rekomendasi dari API 653.

\section{Data Tangki}

Diketahui data geometri dan properti material tangki secara umum adalah sebagaimana berikut.

\section{Tabel 1. Data tangki}

\begin{tabular}{|c|c|c|c|c|c|}
\hline \multicolumn{6}{|l|}{ Tank Data } \\
\hline Tank Name & & & $=$ & & \\
\hline Water Level & & & $=$ & - & $\mathrm{m}$ \\
\hline O.D Tank & & & $=$ & 35.01 & $\mathrm{ft}$ \\
\hline No. of survey point, & & & $=$ & 16 & EA \\
\hline \multicolumn{2}{|c|}{ Arc length between measurement points, } & L & $=$ & 6.87 & $\mathrm{ft}$ \\
\hline \multicolumn{2}{|c|}{ Yiled strength of the shell material, } & $\mathrm{Y}$ & $=$ & 29732.8 & lbf/in2 \\
\hline Young's Modulus, & & E & $=$ & $2.70 E+07$ & lbf/in2 \\
\hline Tank Height, & & H & $=$ & 29.79 & $\mathrm{ft}$ \\
\hline
\end{tabular}

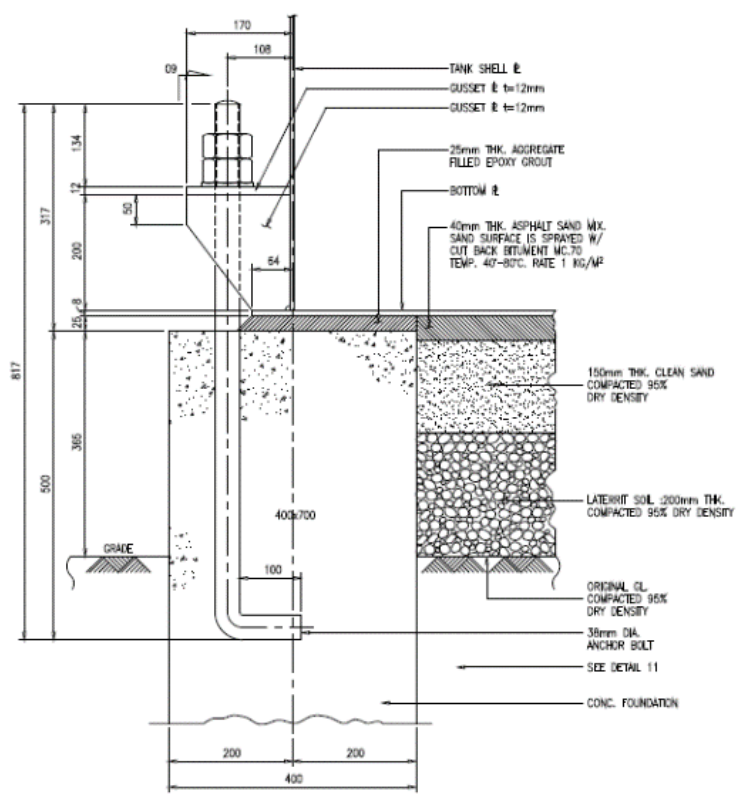

Gambar 6. Potongan pondasi tangki

Tipe pondasi tangki yang digunakan merupakan tipe pondasi tanah dengan ring wall beton. 


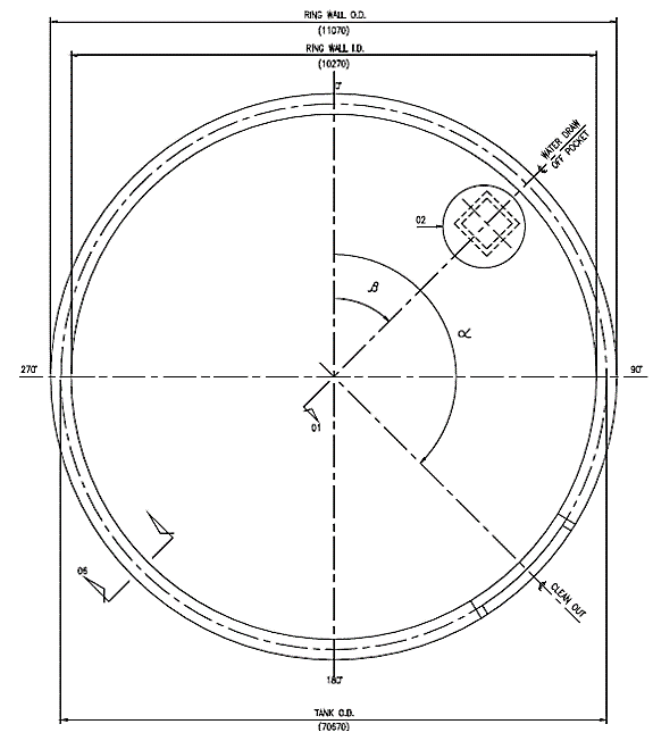

Gambar 7. Tampak atas pondasi tangki

Berdasarkan data lapangan tersebut, penelitian dilakukan dengan mengevaluasi kondisi awal tangki dan menganalisis apakah tangki tersebut masih aman untuk terus dioperasikan atau sudah berada dalam kondisi yang memang membutuhkan perbaikan.

\section{Analisis dan Pembahasan}

Dilakukan pengukuran elevasi permukaan bottom plate yang berada pada pondasi tangki dengan jumlah titik sebanyak 16 buah.
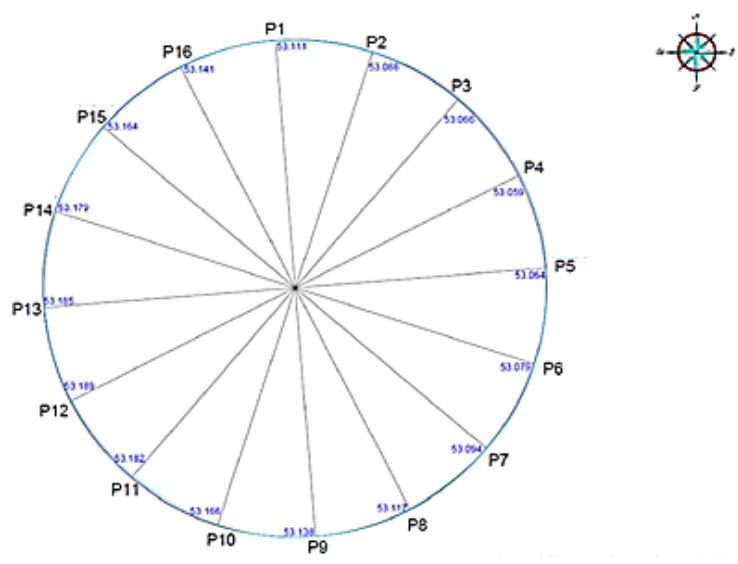

Data pengukuran elevasi di lapangan dapat ditabulasi untuk menghitung besaran nilai out-of-plane settlement (Ui) dan nilai out-ofplane deflection $(\mathrm{Si})$.

Metoda coba-coba untuk nilai a, b dan c yang optimum (persamaan 5) digunakan sehingga diperoleh nilai $\mathrm{R}>0,9$. Untuk perhitungan kali ini setelah beberapa kali coba-coba menggunakan spread sheet, diperoleh nilai $\mathrm{a}=53127, \mathrm{~b}=65$ dan $\mathrm{c}=82$ sehingga diperoleh nilai $\mathrm{R}=0,998$. Dengan demikian, kurva cosine yang dibuat dapat digunakan sebagai acuan settlement untuk tipe body rigid tilting settlement sesuai rujukan dari API 653.

Elev pred. $a+b \times \cos (\theta+c)$
\begin{tabular}{|c|c|}
\hline Prediction \\
\hline$a$ & 53127 \\
\hline$b$ & 65 \\
\hline$c$ & 82 \\
\hline
\end{tabular}

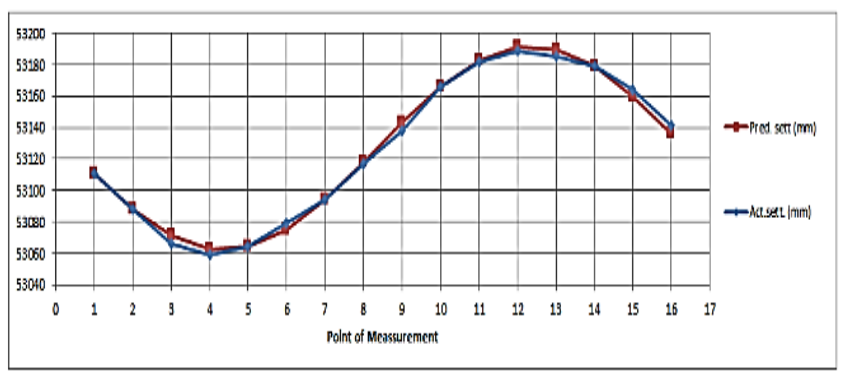

$$
\begin{array}{lcl}
R^{2}= & (\text { Syy }- \text { SSE }) / \text { Sy } \\
\text { Syy } & 33721.75 \\
\text { SSE } & 153.82 \\
R= & 0.998>0.9 ; \text { OK! }
\end{array}
$$

\section{Gambar 9. Kurva Cosine}

Karena diperoleh nilai $\mathrm{R}>0,9$ maka tipe penurunan yang terjadi pada tangki dapat dikategorikan sebagai penurunan body rigid tilting settlement, dimana dianggap pondasi berputar terhadap satu poros bidang. Perhitungan batas penurunan yang diijinkan (Smax) dapat diperoleh sebagai berikut.

$$
\begin{aligned}
S_{\text {max }} & =\frac{\left(L^{2} \times Y \times 11\right)}{2[(E \times H)]} \\
& =\frac{\left(6,87^{2} \times 29732,8 \times 11\right)}{2[(2,7.1 E 7 \times 29,79)]}
\end{aligned}
$$




$$
\begin{aligned}
& =0,01 \mathrm{ft} \\
& =2,9 \mathrm{~mm}
\end{aligned}
$$

Besaran nilai $\mathrm{Si}$, Out-of-plane deflection untuk tiap titik pengukuran jika dibandingkan dengan kriteria batas penurunan yang diijinkan (persamaan 5) dapat ditampilkan dalam tabel dan grafik di bawah.

\section{Tabel 2. Tabulasi perhitungan Ui dan $\mathrm{Si}$}
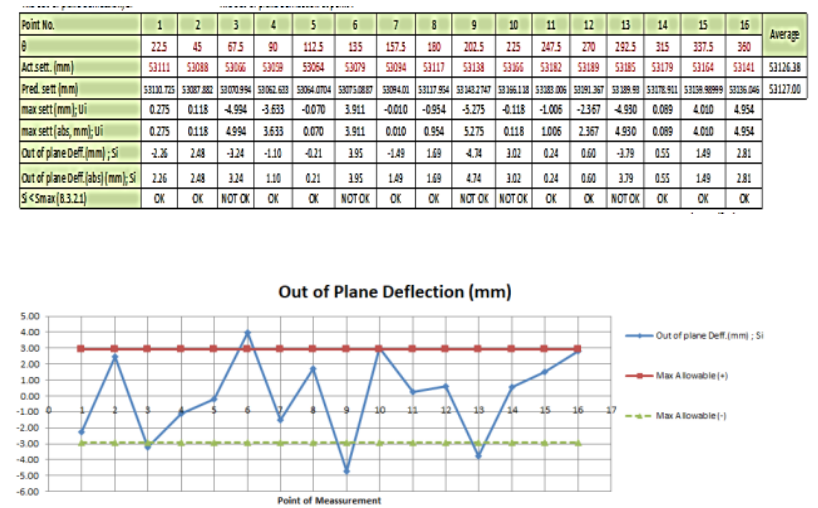

Gambar 10. Grafik Si vs Smax

Berdasarkan nilai Si di tiap titik, diketahui bahwa beberapa titik pada dinding tangki telah mengalami penurunan melebihi dari batas ijin penurunan sesuai API 653. Hal ini ditunjukkan dengan nilai Si yang melebihi nilai Smax.

Upaya perbaikan disarankan agar tangki dapat kembali dapat beroperasi secara penuh. Indikasi penurunan berlebih dapat juga memperlihatkan kemungkinan terjadinya kriteria lainnya yang tidak terpenuhi pada tangki sehingga disarankan perlunya evaluasi pengukuran terhadap ketegakan tangki (tiltting assessment), survey terhadap kondisi settlement pada pelat lantai dasar di dalam tangki, ketebalan material tangki serta kebundaran dari dinding tangki (roundness) untuk mengidentifikasi kerusakan lainnya yang mungkin telah terjadi pada tangki sehinga penentuan perbaikan pada tangki dapat menjadi satu rekomendasi lengkap dalam satu metoda rencana kerja perbaikan kedepannya.

Untuk dapat menganalisis besarnya penurunan di waktu selanjutnya, diperlukan pengambilan undisturb sample di area pondasi untuk sampel pengujian konsolidasi di laboratorium. Parameter tanah yang diperlukan adalah data properti tanah serta parameter kuat geser tanah.

\section{Kesimpulan}

Hasil penelitian menunjukkan bahwa penurunan tangki di beberapa titik telah melebih batas penurunan maksimum (out of plane settlement, Smax) sesuai API 653 pasal B.3.2.2 sehingga diperlukan adanya perbaikan lebih lanjut.

Sebelum metoda perbaikan tangki diputuskan, perlu dilakukan evaluasi kondisi tangki terhadap ketegakan tangki (tilting), inspeksi internal tangki meliputi settlement di bottom plate, ketebalan material sisa tangki serta survey terhadap kebundaran tangki (roundness) sehingga diperoleh metoda perbaikan yang tepat dan terarah.

\section{Daftar Pustaka}

API 653, Tank Inspection, Repair, Alteration, and Reconstruction, fifth edition, 2014.

API 650, Welded Tanks for Oil , Twelfth edition, 2016.

Nurpadmi, Otomasi Sistem Pengosongan Tangki T101 dan T102 untuk PengolahanKilang PPSDM Migas Menggunakan PLC, Swara Patra Vol. 8 No. 2, PPSDM Migas, 2018.

Widawardhana, Datta, Pemilihan Jenis Pondasi pada Tangki Timbun Aboveground, Webinar Sipilpedia sesi 14, 2020. 